\title{
Author Correction: Future climate risk from compound events
}

\section{Jakob Zscheischler (1), Seth Westra, Bart J. J. M. van den Hurk (1), Sonia I. Seneviratne (1), Philip J. Ward (D), Andy Pitman,} Amir AghaKouchak (D), David N. Bresch, Michael Leonard, Thomas Wahl and Xuebin Zhang

Correction to: Nature Climate Change https://doi.org/10.1038/s41558-018-0156-3, published online 14 May 2018.

In the version of this Perspective originally published, the names of the authors of reference 13 were presented incorrectly, with their first names in place of their last names; this has been corrected accordingly to read: "Diakakis, M., Deligiannakis, G., Katsetsiadou, K. \& Lekkas, E.".

Published online: 20 June 2018

https://doi.org/10.1038/s41558-018-0220-z

\section{Author Correction: Species' traits influenced their response to recent climate change}

Michela Pacifici, Piero Visconti, Stuart H. M. Butchart, James E. M. Watson, Francesca M. Cassola and Carlo Rondinini

Correction to: Nature Climate Change https://doi.org/10.1038/nclimate3223, published online 13 February 2017.

In the Supplementary Information PDF published with this Letter, under the heading 'Keywords used to select the papers for the literature review, operator $\left(^{*}\right)$ use in the search strings is inconsistent and at times incorrect. In addition, the full list of references shortlisted from the Web of Science search criteria used in this study was not provided. The amended PDF is available as Supplementary Information to this Correction; those references not cited in the main paper and Methods have been included: refs 59-124 relate to mammals and refs $125-190$ to birds.

Published online: 16 July 2018

https://doi.org/10.1038/s41558-018-0229-3

\section{Additional information}

Supplementary information is available for this paper at https://doi.org/10.1038/s41558-018-0229-3.

\section{Author Correction: Air quality co-benefits of carbon pricing in China}

Mingwei Li (D), Da Zhang, Chiao-Ting Li, Kathleen M. Mulvaney, Noelle E. Selin (D) and Valerie J. Karplus (D)

Correction to: Nature Climate Change https://doi.org/10.1038/s41558-018-0139-4, published online 23 April 2018.

In the version of the Supplementary Information file originally published alongside this Article, on page S2 'No Policy' emissions values were incorrect for black carbon (BC) and primary organic carbon (OC): the sentence: "BC is $195 \%$ higher, and OC is $240 \%$ higher" should have read: "BC is $95 \%$ higher, and OC is $140 \%$ higher". The Supplementary file has now been amended. 